\title{
The Effect of Nitrogen-Doped ATO Nanotubes on Radical Multiplication of Buffer Media by Visible Light Photocatalysis Rather UV
}

\author{
Kan-Hung Hu, ${ }^{1}$ Shing-Hoa Wang, ${ }^{1,2}$ Todd Hsu, ${ }^{2,3}$ Chien-Chon Chen, ${ }^{4}$ Tai-Yuan Lin, ${ }^{5}$ \\ Huei-Ting Tsai, ${ }^{3}$ and Hsiang-Ho Chiang ${ }^{1}$ \\ ${ }^{1}$ Department of Mechanical and Mechatronic Engineering, National Taiwan Ocean University, Keelung 20224, Taiwan \\ ${ }^{2}$ Center of Excellence for Marine Bioenvironment and Biotechnology, National Taiwan Ocean University, Keelung 20224, Taiwan \\ ${ }^{3}$ Institute of Bioscience and Biotechnology, National Taiwan Ocean University, Keelung 20224, Taiwan \\ ${ }^{4}$ Department of Energy and Resources, National United University, Miaoli 36003, Taiwan \\ ${ }^{5}$ Institute of Optoelectronic Sciences, National Taiwan Ocean University, Keelung 20224, Taiwan
}

Correspondence should be addressed to Shing-Hoa Wang, shwang@ntou.edu.tw and Todd Hsu, toddhsu@ntou.edu.tw

Received 25 May 2012; Revised 1 September 2012; Accepted 1 September 2012

Academic Editor: Sheng-Rui Jian

Copyright (๑) 2012 Kan-Hung Hu et al. This is an open access article distributed under the Creative Commons Attribution License, which permits unrestricted use, distribution, and reproduction in any medium, provided the original work is properly cited.

The use of $\mathrm{TiO}_{2}$ in photodynamic therapy for the treatment of cancer has generally been studied in cultured cancer cells in serumcontaining RPMI 1640 medium under visible light application rather than ultraviolet (UV) light. An ordered channel array of $\mathrm{N}$-doped anodic titanium dioxide (ATO) has been successfully made for visible light application. ATO nanotubes in the anatase form with a length of $10 \mu \mathrm{m}$ are more effective than nanotubes of $1.8 \mu \mathrm{m}$ in length as a photocatalyst for radical multiplication in buffer solution by generating hydroxyl radicals and superoxide radical anions under UV-A exposure. Only the N-doped ATO is applicable to visible light photocatalysis for radical multiplication in RPMI $1640+1 \%$ FBS and acrylamide, a free radical carrier.

\section{Introduction}

$\mathrm{TiO}_{2}$ in the anatase crystalline form, which behaves as a classical n-type semiconductor, has been widely studied for photocatalytic and photochemical applications due to its excellent photocatalytic properties, such as strong oxidizing power, for the decomposition of unwanted organic compounds, as well as inorganic and microbial pollutants [1-3]. ATO (anodic titanium oxide) is excited only by ultraviolet (UV) radiation $(\lambda<380 \mathrm{~nm})$ in photoresponse, which restricts its applications in the visible light range. To enhance the efficiency in the visible range, there has been extensive investigation of approaches that involved doping of suitable impurities into the $\mathrm{TiO}_{2}$ crystal structure to improve its response to the natural solar spectrum around $\lambda=500 \mathrm{~nm}$.

Considerable success has been achieved in increasing the photocatalytic activity by decreasing the band gap of ATO under optimal conditions. This leads to higher photocurrents under visible irradiation. $\mathrm{N}$-doping of ATO is the most promising path toward narrowing the band gap energy, as it does not cause structural damage that strongly reduces the photon conversion efficiency. The efficiency of nitrogen doping is strongly dependent on the kind of nitrogen compounds, treatment method, and treatment temperature that are used [4]. Photodynamic therapy is a relatively new treatment for certain cancers, such as endobronchial and esophageal cancers [5]. The photocytotoxic effects of ATO have been normally studied on cell lines cultured in various media with a $\mathrm{pH}$ suitable for cell survival. Cancerous cell lines, such as HeLa cells and human adenocarcinoma cells, are generally maintained in RPMI 1640 (Roswell Park Memorial Institute 1640) medium that contains calf serum or FBS (fetal bovine serum) [6]. The serum included in these media provides protein factors that are required for cell growth and attachment [7].

Few reports have been published on the visible light photocatalysis and size effects of ATO applied to a buffer medium for cell cultivation. The aim of this study is to 


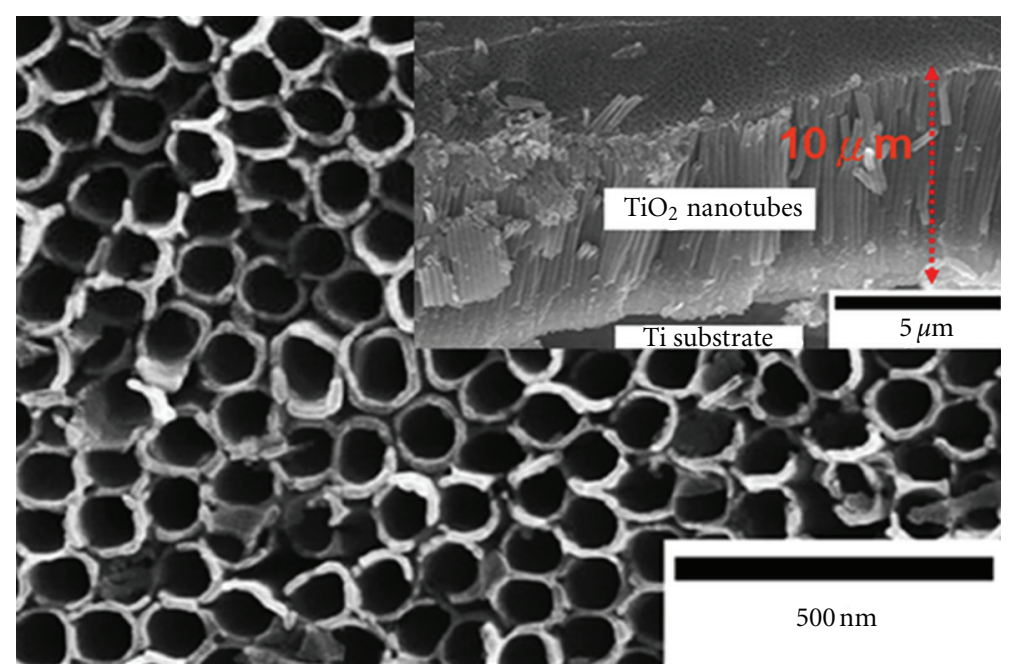

FIGURE 1: SEM top views of the nanotubular layer of $\mathrm{N}$-doping in a mixed gas of $\mathrm{N}_{2} / \mathrm{Ar}$. The inset shows the thickness of nanotube layer in cross-section.

investigate the effect of visible light photocatalysis of $\mathrm{N}$ doped ATO on radical multiplication in serum-containing RPMI 1640, when compared to the effects of ultraviolet radiation (UV). The acrylamide solution was chosen as a positive control for radical multiplication because it is known as a free radical carrier during gel polymerization reactions [7].

\section{Experimental Methods}

Titanium foil ( $99.7 \%$ purity, $0.127 \mathrm{~mm}$ thick) was annealed in an air furnace at $450^{\circ} \mathrm{C}$ for $3 \mathrm{~h}$ to release stress. It was then rinsed in deionized water (DI). As-prepared samples were clamped onto the holder, immersed in the electrolyte, and anodized at $60 \mathrm{~V}$ for $1 \mathrm{~h}$. An ordered channel-array anodic ATO nanotube layer was formed. The length of the ATO nanotubes was about $10 \mu \mathrm{m}$, which was achieved in an electrolyte composed of 0.5 -wt $\%$ ammonium fluoride mixed with ethylene glycol at $60 \mathrm{~V}$ for $1 \mathrm{~h}$. The $1.8 \mu \mathrm{m}$ length of the ATO nanotubes was performed in an aqueous solution comprising $0.5 \%$ hydrofluoric acid and deionized water for $1 \mathrm{~h}$ at $15 \mathrm{~V}$. The anodization was conducted in a twoelectrode cell, using a platinum foil as the counter electrode under $15 \mathrm{~V}$ for the $1.8 \mu \mathrm{m}$ nanotubes and $60 \mathrm{~V}$ for $10 \mu \mathrm{m}$ nanotubes at $25^{\circ} \mathrm{C}$ without stirring. After anodization, the undoped samples were annealed $450^{\circ} \mathrm{C}$ for $3 \mathrm{~h}$ to form the pure anatase structure in perfect channel array of nanotubes with the best photocatalytic efficiency under UV. In order to compare the nitrogen doping effect, the $10 \mu \mathrm{m}$ thick ATO were chosen and annealed at $550^{\circ} \mathrm{C}$ for $4 \mathrm{~h}$ in Ar for undoped samples and in a mixed atmosphere of $40-\mathrm{vol} \% \mathrm{~N}_{2} / 60$ vol\% Ar for N-doped samples, respectively. The band gap of photoluminescence (PL) for samples was measured using a He-Cd laser as the light source with an excitation wavelength of 325-700 nm. The chemical composition of the N-doped samples was analyzed by X-ray photoelectron spectroscopy with a resolution of $0.1 \mathrm{eV}$. $\mathrm{Al} \mathrm{K} \alpha$ monochromatic radiation
( $15 \mathrm{keV} ; 200 \mathrm{~W}$ ) was utilized as the excitation source, and the results showed the standard peaks of Ti at a binding energy of $459 \mathrm{eV}, \mathrm{O}$ at $529 \mathrm{eV}, \mathrm{C}$ at $285 \mathrm{eV}$, and $\mathrm{N}$ at $396 \mathrm{eV}$ and $400 \mathrm{eV}$. The photocatalytic effect of annealed ATO and Ndoped ATO was determined in RPMI $1640+1 \%$ FBS and $10 \%(\mathrm{w} / \mathrm{v})$ acrylamide solution. The media were irradiated with two kinds of light sources, including UV-A (wavelength of $A=366 \mathrm{~nm}$ ) and visible light for $100 \mathrm{~s}$ after stabilization for a period of $100 \mathrm{~s}$. The distance between the sample and the light source was approximately $10 \mathrm{~cm}$. The intensity of the UV-A irradiance was $0.1 \mathrm{~mW} / \mathrm{cm}^{2}$ as measured using a UV meter. One of two platinum wires as a working electrode, the other as an auxiliary electrode, and $\mathrm{Ag} / \mathrm{AgCl}$ as a reference electrode were immersed into the well of a tissue culture plate containing ATO, which was filled with a specific medium. The electrical potential of the well was recorded under exposure to the two different types of irradiation aforementioned. The redox potential changes produced by ATO in RPMI 1640 and acrylamide solution under UV-A or visible light were determined under five tests for each case of several independent experiments.

\section{Results and Discussion}

The morphology of the top views of the $\mathrm{N}$-doped (in Figure 1) ATO shows self-organized $\mathrm{TiO}_{2}$ nanotubular layers after treatment at $550^{\circ} \mathrm{C}$ for $4 \mathrm{~h}$ in a mixed atmosphere of $\mathrm{N}_{2} / \mathrm{Ar}$. The insets show that the thickness of the nanotubular layer was pproximately $10 \mu \mathrm{m}$. A similar morphology appears for $1.8-\mu \mathrm{m}$ thick, undoped nanotube arrays after $450^{\circ} \mathrm{C}$ annealing.

To verify the wavelength-related band gap energies of various annealed $\mathrm{TiO}_{2}$ nanotube arrays, photoluminescence (PL) spectra were measured at a temperature of $10 \mathrm{~K}$. The $\mathrm{N}$-doped ATO nanotubes $\left(\mathrm{TiO}_{2-x} \mathrm{~N}_{x}\right)$ had emission energy of approximately $2.47 \mathrm{eV}$ shifted from original $3.18 \mathrm{eV}$ of undoped ATO nanotubes, which corresponds to a longer 


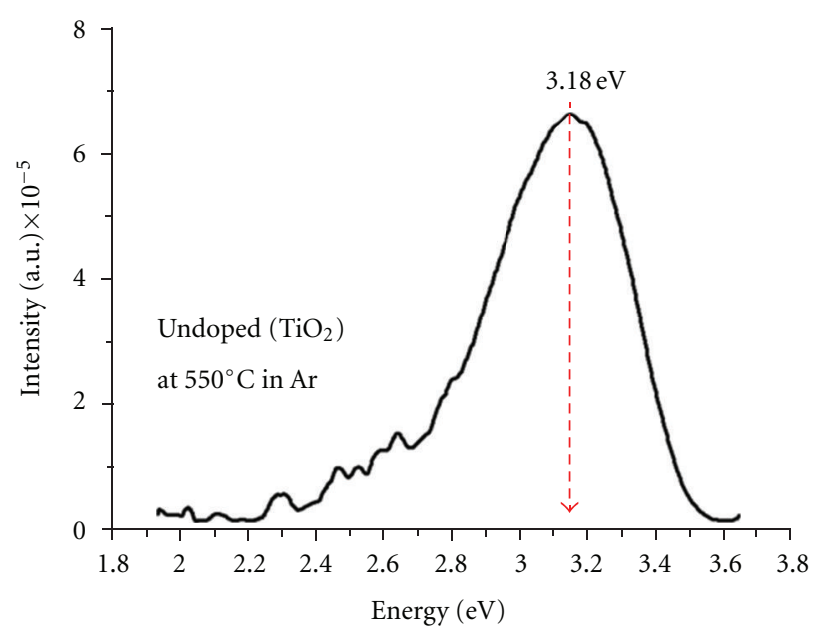

(a)

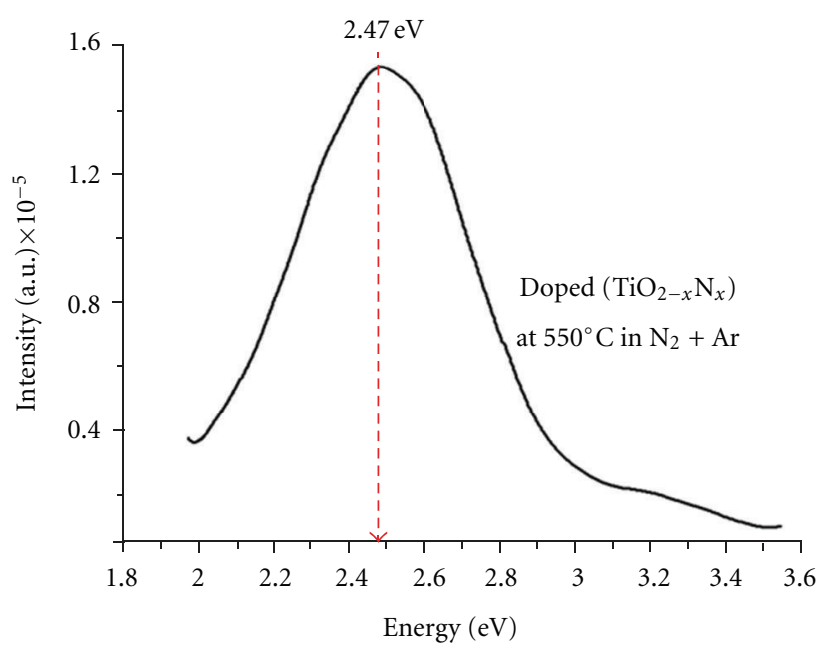

(b)

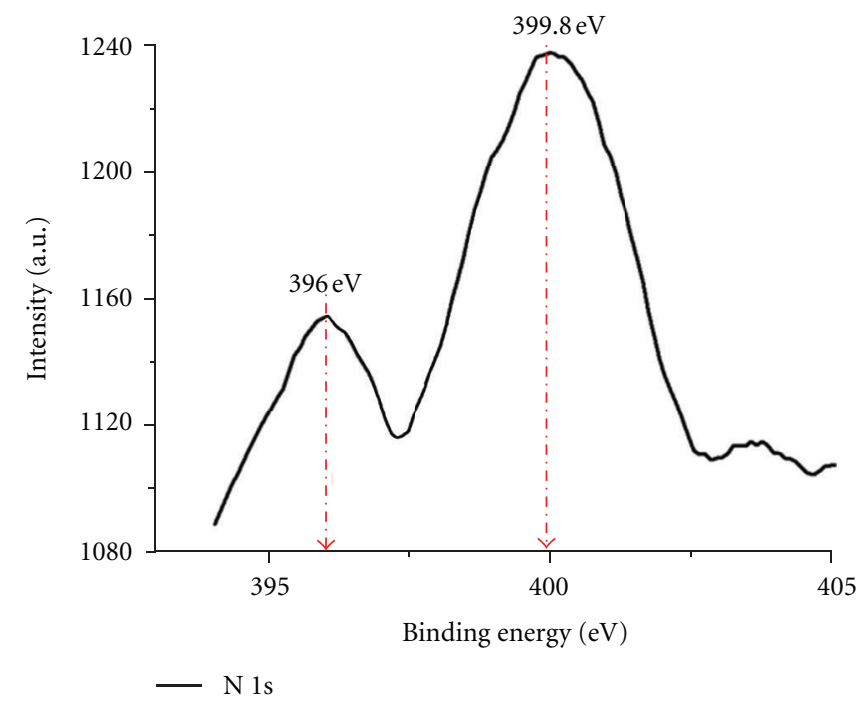

(c)

FIgure 2: PL of (a) undoped ATO, (b) N-doped ATO, and (c) XPS spectra of the nitrogen-doped ATO nanotubular layer of the sample in Figure 1.

wavelength of $500 \mathrm{~nm}$ and is feasible for a visible light source (Figure 2). To check whether the nitrogen was doped into the $\mathrm{TiO}_{2}$, the chemical composition of the sample surface was identified by X-ray photoemission spectroscopy (XPS), through chemical element electron configuration shifts due to changes in the chemical bonding of the sample atoms. As shown in Figure 2(c), the 1s core levels of the $\mathrm{N}$ spectrum for the $\mathrm{N}$-doped $\mathrm{TiO}_{2}$ nanotubular layer in Figure 1. The nitrogen spectral signal (N 1s) reveals two peaks, at $396 \pm$ $0.2 \mathrm{eV}$ and $400 \pm 0.2 \mathrm{eV}$. The former corresponds to a $\beta-\mathrm{N}$ state, which is essentially atomic $\mathrm{N}$ or $\mathrm{NO}$ in the form of mixed titanium oxide-nitride $\left(\mathrm{TiO}_{2-x} \mathrm{~N}_{x}\right)$, and the latter is assigned to the $\gamma$-N state, which is molecularly chemisorbed $\mathrm{N}_{2}$. This result indicates that indeed $\mathrm{N}$-doped heat treatment successfully leads to the substitution of some oxygen sites by nitrogen $[8,9]$.
The accuracy of our measurement for the potential changes after photocatalytic reaction is shown by the small ( 2 to $5 \%$ ) variation of the mean in Figure 3. Each bar graph shown in Figure 3 indicates the mean and standard deviation of several independent experiments. The effect of nanotube length on redox potentials of undoped ATO in the cancer cell culture medium RPMI $1640+1 \%$ FBS and in acrylamide, a well-known free radical carrier, is compared in Figure 3(a) after photocatalysis under UV-A and visible light, respectively. In the case of undoped ATO annealed at $450^{\circ} \mathrm{C}$ with pure anatase structure in Figure $3(\mathrm{a})$, the redox potentials of photocatalysis in longer nanotubes of $10 \mu \mathrm{m}$ about $3.80 \mathrm{mV}$ for acrylamide and about $4.00 \mathrm{mV}$ for RPMI $1640+1 \%$ FBS were higher than that in shorter nanotubes of $1.8 \mu \mathrm{m}$ about $1.75 \mathrm{mV}$ and $1.80 \mathrm{mV}$ under UV-A exposure. Perhaps a longer ATO nanotube $(10 \mu \mathrm{m})$ 


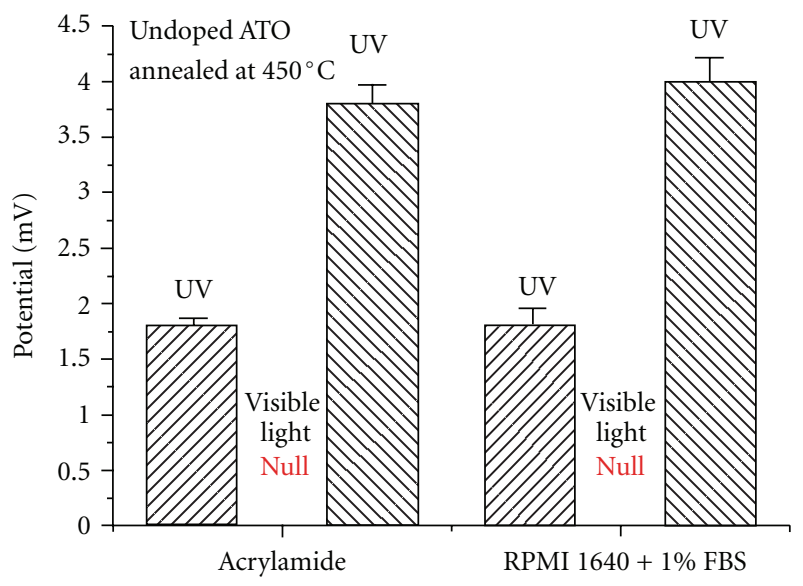

पIJ $1.8 \mu \mathrm{m}$
एाण Visible light
Mाग $10 \mu \mathrm{m}$

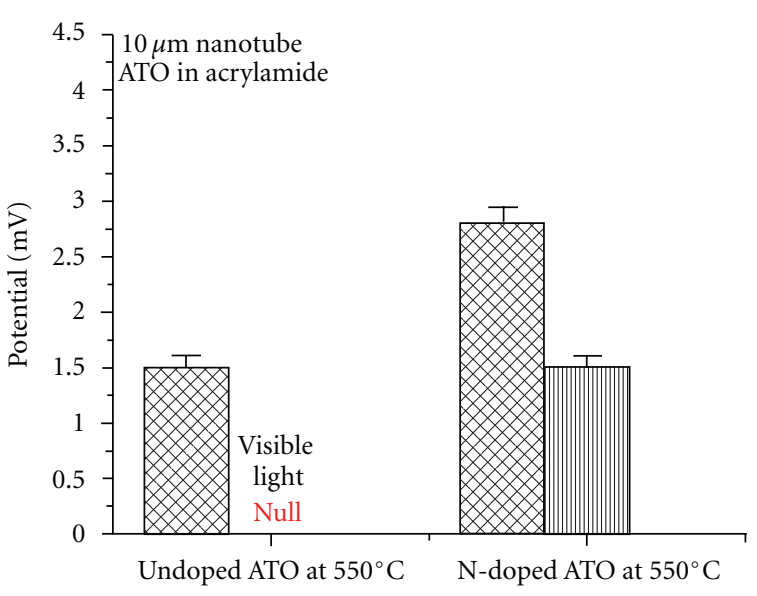

$\infty$ UV

血血 Visible light (a) (b)

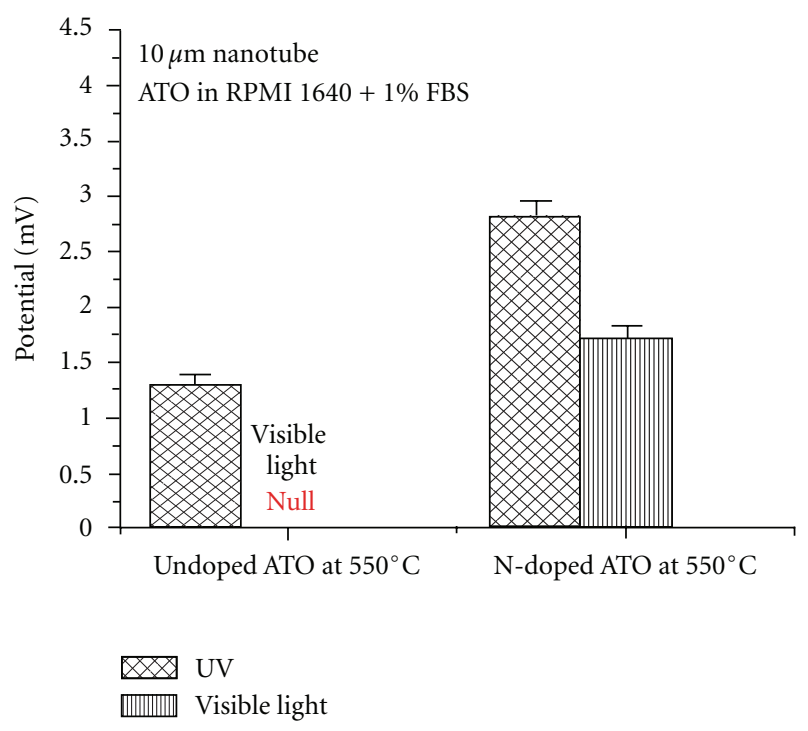

(c)

Figure 3: Potential change after photocatalytic reaction of (a) the $1.8 \mu \mathrm{m}$ and $10 \mu \mathrm{m}$ thick layer of nanotubes with pure anatase structure, in various buffer media under UV-A and visible light exposure, and the $10 \mu \mathrm{m}$ thick ATO samples in (b) acrylamide and (c) RPMI $+1 \%$ FBS under two kinds of light sources.

has more area for photocatalytic activity and low trapping and electron-hole pair recombination effects. Therefore, an ATO with a long nanotube length has a higher reactive potential than an ATO with the short nanotube length. Valence electrons under UV-A were excited to the conduction band for $1.8 \mu \mathrm{m}$ and $10 \mu \mathrm{m}$ thick undoped ATO, whereas the same samples exhibit nearly null potential, or no reaction, under visible light in both acrylamide solution and RPMI $1640+1 \%$ FBS buffer in Figure 3(a). Because undoped ATO does not include the chemical compound titanium oxidenitride $\left(\mathrm{TiO}_{2-x} \mathrm{~N}_{x}\right)$ aforementioned to produce a midgap band, there is insufficient energy or intensity to excite the electron.
For comparison of the N-doping effect, Figures 3(b) and 3 (c) show the results of light types on the photocatalytic redox potential for undoped and $\mathrm{N}$-doped ATO with the same $10 \mu \mathrm{m}$ long nanotubes. The redox potential of acrylamide (Figure 3(b)) and RPMI $1640+1 \%$ FBS (Figure 3(c)) under UV-A radiation has a certain amount of change by using $\mathrm{N}$-doped ATO at $550^{\circ} \mathrm{C}$, although its magnitude about $2.88 \mathrm{mV}$ and $2.80 \mathrm{mV}$ is not as strong as that of using undoped ATO annealed at $450^{\circ} \mathrm{C}$ with full anatase at about $3.80 \mathrm{mV}$ and $4.00 \mathrm{mV}$. In the meantime, redox potential of acrylamide (Figure 3(b)) about $1.50 \mathrm{mV}$ and of RPMI $1640+1 \%$ FBS (Figure 3(c)) about $1.30 \mathrm{mV}$ under UVA radiation also demonstrated the relatively lowest value 


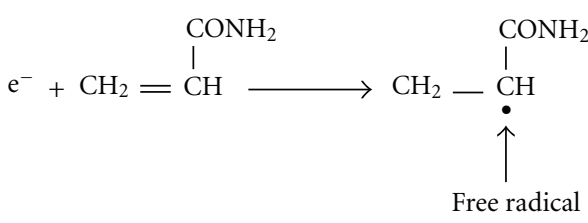

SCHEMe 1

in using undoped ATO annealed at $550^{\circ} \mathrm{C}$ than at $450^{\circ} \mathrm{C}$ (Figure 3(a)), caused by a small amount of residual rutile coexisting in the anatase at $550^{\circ} \mathrm{C}$. This result is consistent with literature reports detailing that titanium oxide in the full anatase form has a better catalytic performance than that of either the rutile form, mixtures of anatase and rutile, or amorphous structures [10]. Eventually similar to the longer $10 \mu \mathrm{m}$ nanotubular ATO, the undoped ATO annealed at $550^{\circ} \mathrm{C}$ appears null potential, or no reaction under visible light in both acrylamide (Figure 3(b)) and RPMI $1640+$ $1 \%$ FBS (Figure $3(\mathrm{c})$ ). The advantage of N-doped ATO is that the reaction of the redox potential occurs effectively under visible light, in addition to UV-A, about $1.50 \mathrm{mV}$ for acrylamide as shown in Figure 3(b) and about $1.75 \mathrm{mV}$ for RPMI $1640+1 \%$ FBS in Figure 3(c). In other words, only N-doped ATO can be applicable to the visible light for photocatalysis. This attributes to the chemical compound titanium oxide-nitride $\left(\mathrm{TiO}_{2-x} \mathrm{~N}_{x}\right)$ formation to produce a midgap band with $2.47 \mathrm{eV}$, resulting in the demand of the appropriate small energy or intensity to excite the electron with a loner wavelength of $500 \mathrm{~nm}$. The anatase phases of annealed ATO under UV-A radiation and N-doped ATO under both of UV-A and visible light have the ability to photocatalyze and activate the culture media to release free hydroxyl radicals or oxygen radicals effectively by breaking a deoxyribonucleic acid (DNA) supercoiled plasmid after light irradiation $[11,12]$. The increase in the redox potential after UV-A and visible light irradiation in the acrylamide medium in the presence of ATO and N-doped ATO could be explained by the electron-accepting capacity of acrylamide. $\left(\mathrm{CH}_{2} \mathrm{CHCONH}_{2}\right)$, as shown in Scheme 1 .

Consequently, many free radicals are brought into intensive contact with the acrylamide molecules $[6,11,12]$. Previous studies have demonstrated that the photocytotoxicity of ATO depends on the concentration of the photocatalyst, the dose of irradiating light, the morphology of $\mathrm{TiO}_{2}$, and the incorporation of the photosensitizer into the target cells [13]. The results suggest that the electron-accepting capacity of the aqueous environment around or within target cells might influence the photocytotoxic activity of ATO on target cells. The N-doped ATO under visible can also cause the breakage of a deoxyribonucleic acid (DNA) supercoiled plasmid, in addition to sterilize the environment. Although, it has been reported that there is no direct relationship between the visible light photoactivity and surface nitrogen concentration of nitrogen-doped $\mathrm{TiO}_{2}$ by the thermal treatment of nanotube titanic acid in an $\mathrm{NH}_{3}$ flow from $400^{\circ} \mathrm{C}$ to $700^{\circ} \mathrm{C}$ [14]. The future research is encouraged to investigate the effect of $\mathrm{N}$ doped ATO concentration on visible light photocatalysis for radical multiplication of buffer media.

\section{Conclusion}

The crystal structure and nanotube length influence the magnitude of the radical multiplication and photocatalytic potential of acrylamide and RPMI $1640+1 \%$ FBS. The longer nanotubes have more area for photocatalytic activity, resulting in less trapping or electron-hole pair recombination. Only $\mathrm{N}$-doped titanium oxide-nitride (ATO) is feasible for use in cell cultivation media in visible light besides UV irradiation, resulting from the existence of the midgap band for absorbing the $500 \mathrm{~nm}$ wavelength. The $\mathrm{N}$-doped ATO under visible can also cause the breakage of a deoxyribonucleic acid (DNA) supercoiled plasmid, in addition to sterilize the environment.

\section{Acknowledgments}

The authors would like to thank the Center of Excellence for Marine Bioenvironment and Biotechnology of National Taiwan Ocean University, Keelung, Taiwan for financially supporting this research under Contracts nos. 97529002K2 and 98529002 J2.

\section{References}

[1] A. Mills and S. L. Hunte, "An overview of semiconductor photocatalysis," Journal of Photochemistry and Photobiology A, vol. 108, no. 1, pp. 1-35, 1997.

[2] B. O’Regan and M. Grätzel, "A low-cost, high-efficiency solar cell based on dye-sensitized colloidal $\mathrm{TiO}_{2}$ films," Nature, vol. 353, no. 6346, pp. 737-740, 1991.

[3] S. K. Joung, T. Amemiya, M. Murabayashi, and K. Itoh, "Relation between photocatalytic activity and preparation conditions for nitrogen-doped visible light-driven $\mathrm{TiO}_{2}$ photocatalysts," Applied Catalysis A, vol. 312, no. 1-2, pp. 20-26, 2006.

[4] J. M. Macak, A. Ghicov, R. Hahn, H. Tsuchiya, and P. Schmuki, "Photoelectrochemical properties of N-doped self-organized titania nanotube layers with different thickness," Journal of Materials Research, vol. 21, no. 11, pp. 2824-2828, 2006.

[5] B. W. Henderson, C. Daroqui, E. Tracy et al., "Cross-linking of signal transducer and activator of transcription 3-a molecular marker for the photodynamic reaction in cells and tumors," Clinical Cancer Research, vol. 13, no. 11, pp. 31563163, 2007.

[6] K. Fuller, B. Kirstein, and T. J. Chambers, "Murine osteoclast formation and function: differential regulation by humoral agents," Endocrinology, vol. 147, no. 4, pp. 1979-1985, 2006.

[7] I. R. Freshney, Culture of Animal Cells: A Manual of Basic Technique, Wiley-Liss, New York, NY, USA, 3rd edition, 1983.

[8] J. M. Macak, M. Zlamal, J. Krysa, and P. Schmuki, "Selforganized $\mathrm{TiO}_{2}$ nanotube layers as highly efficient photocatalysts," Small, vol. 3, no. 2, pp. 300-304, 2007.

[9] M. Pratap Reddy, H. H. Phil, and M. Subrahmanyam, "Photocatalytic disinfection of escherichia coli over titanium (IV) oxide supported on $\mathrm{H} \beta$ zeolite," Catalysis Letters, vol. 123, no. 1-2, pp. 56-64, 2008.

[10] Y. Lai, L. Sun, Y. Chen, H. Zhuang, C. Lin, and J. W. Chin, "Effects of the structure of $\mathrm{TiO}_{2}$ nanotube array on Ti substrate on its photocatalytic activity," Journal of the Electrochemical Society, vol. 153, no. 7, pp. D123-D127, 2006. 
[11] T. G. Cooper, The Tools of Biochemistry, Wiley, New York, NY, USA, 1977.

[12] C. K. Yu, K. H. Hu, S. H. Wang et al., "Photocatalytic effect of anodic titanium oxide nanotubes on various cell culture media," Applied Physics A, vol. 102, no. 2, pp. 271-274, 2011.

[13] H. Sakai, E. Ito, R. X. Cai et al., "Intracellular $\mathrm{Ca}^{2+}$ concentration change of $\mathrm{T} 24$ cell under irradiation in the presence of $\mathrm{TiO}_{2}$ ultrafine particles," Iochimica et Biophysica Acta, vol. 1200, pp. 259-265, 1994.

[14] C. Feng, Y. Wang, Z. Jin et al., "Photoactive centers responsible for visible-light photoactivity of $\mathrm{N}$-doped $\mathrm{TiO}_{2}$," New Journal of Chemistry, vol. 32, no. 6, pp. 1038-1047, 2008. 

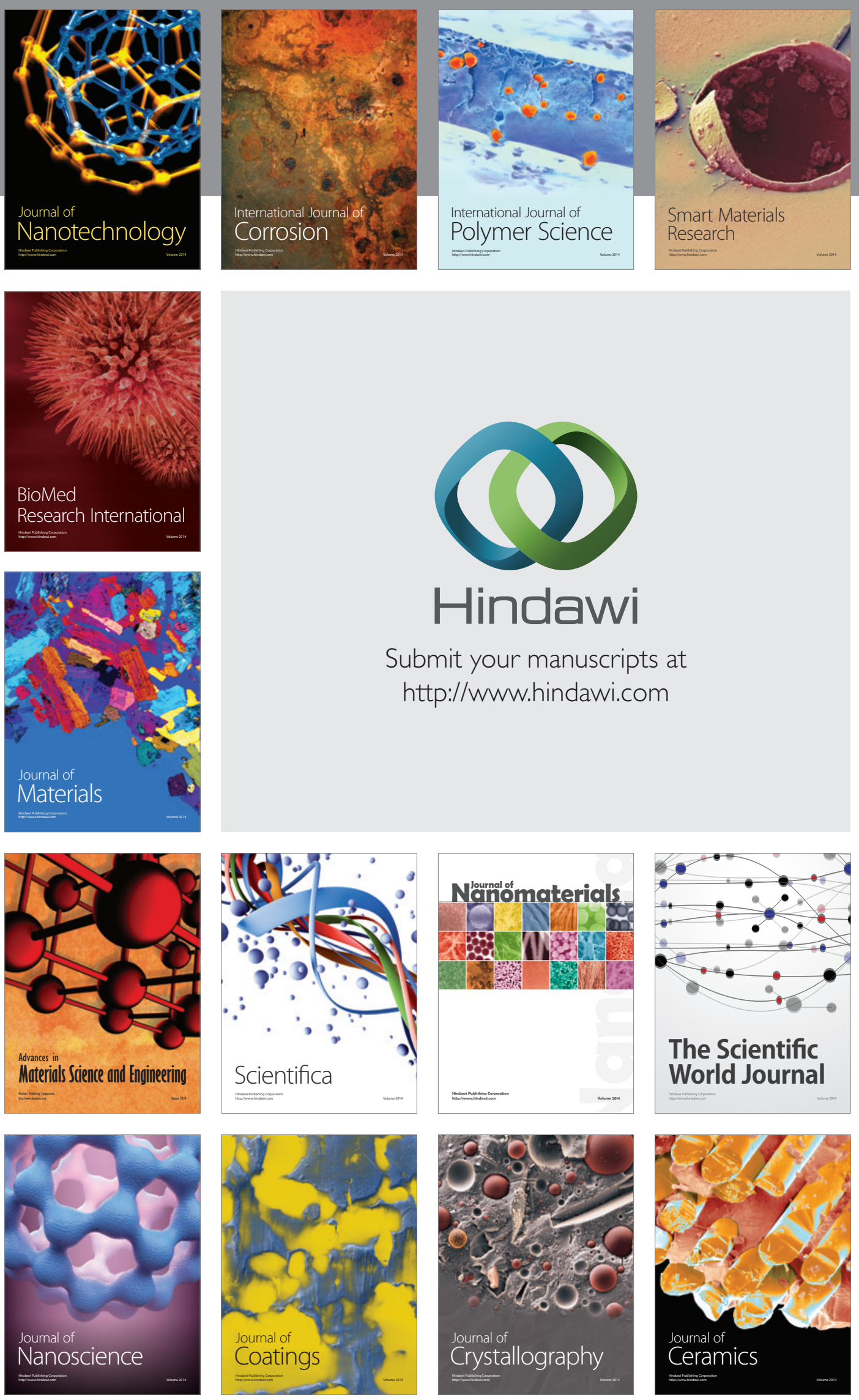

The Scientific World Journal

Submit your manuscripts at

http://www.hindawi.com

\section{World Journal}

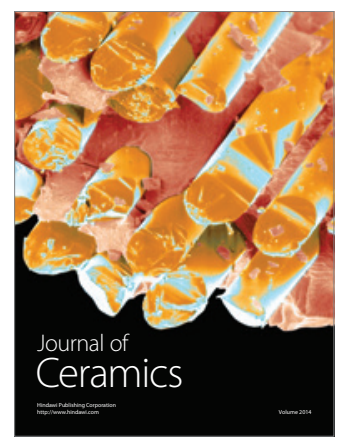

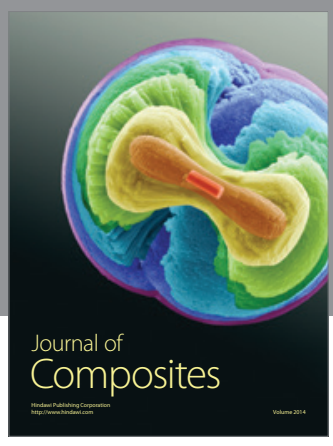
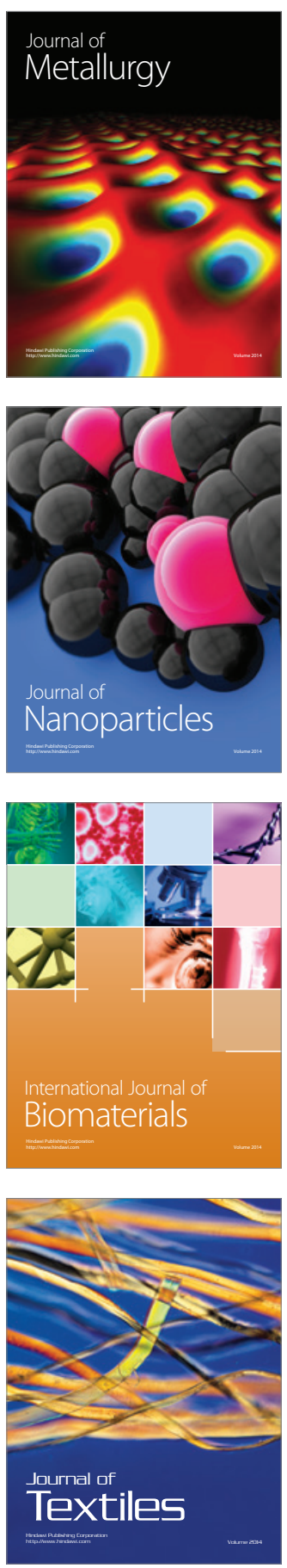